E-JURNAL EKONOMI DAN BISNIS UNIVERSITAS UDAYANA
Available online at https://ojs.unud.ac.id/index.php/EEB/index
Vol. 10 No. 03, March 2021, pages: 127- 134
e-ISSN: 2337-3067

\title{
PENGARUH LITERASI KEUANGAN TERHADAP PERILAKU KEUANGAN MAHASISWA
}

\author{
Wayan Tari Indra Putri ${ }^{1}$ Kadek Nita Sumiari ${ }^{2}$
}

Article history:

Submitted: 18 Desember 2020

Revised: 18 Januari 2021

Accepted: 21 Januari 2021

\section{Keywords:}

Financial literacy;

Financial behaviour;

\section{Kata Kunci:}

Literasi Keuangan;

Perilaku Keuangan;

\section{Koresponding:}

Politeknik Negeri Bali, Bali, Indonesia

Email:

tariindraputri@gmail.com

\section{Abstract}

Having knowledge of financial literacy is a must in order to have a prosperous life. Financial literacy is needed by all people in society to support good financial management.Currently the OJK is working to improve financial inclusion and literacy, especially among students. This step is a form of effort to increase the role of students in the Indonesian economy. As the next generation, a student must have knowledge related to personal financial management. This knowledge will be very useful for students to manage their finances in the future. Four diploma students majoring in Accounting at the Bali State Polytechnic have obtained courses related to finance and investment so that they should have a good level of financial literacy knowledge. The purpose of this research is to examine the effect of financial literacy on student financial behavior. Respondents in this study amounted to 95 people. The data in this study were analyzed using simple linear regression analysis. The results of this study are that there is an influence between financial literacy variables on student financial behavior. The test results show that the better the knowledge or understanding of financial literacy possessed by students, the better the student's ability to implement good financial behavior.

Abstrak
Literasi keuangan sangatlah diperlukan oleh semua kalangan
masyarakat untuk menunjang pengelolaan keuangan yang baik. Saat ini
OJK tengah berupaya untuk meningkatkan inklusi dan literasi keuangan
terutama dikalangan mahasiswa. Langkah ini merupakan salah satu bentuk
upaya meningkatkan peran mahasiswa terhadap perekonomian Indonesia.
Sebagai generasi penerus, seorang mahasiswa harus memiliki pengetahuan
terkait pengelolaan keuangan pribadi. Pengetahuan tersebut akan sangat
berguna bagi mahasiswa untuk mengatur keuangannya dimasa yang akan
datang. Mahasiswa diploma empat jurusan Akuntansi Politeknik Negeri
Bali telah memperoleh matakuliah yang berkaitan dengan keuangan dan
investasi sehingga seharusnya sudah memiliki tingkat pengetahuan literasi
keuangan yang baik. Penelitian ini dilakukan untuk mengetahui pengaruh
literasi keuangan terhadap perilaku keuangan mahasiwa. Responden dalam
penelitian ini berjumlah 95 orang. Adapun hasil dari penelitian ini adalah
terdapat pengaruh antara variabel literasi keuangan terhadap perilaku
keuangan mahasiswa. Hasil pengujian tersebut menunjukan bahwa semakin
baiknya pengetahuan atau pemahaman terkait literasi keuangan yang
dimiliki oleh mahasiswa maka kemampuan mahasiswa tersebut untuk
menerapkan perilaku keuangan akan semakin baik pula.

Politeknik Negeri Bali, Bali, Indonesia

Email: nitasumiari@pnb.ac.id ${ }^{2}$ 


\section{PENDAHULUAN}

Dewasa ini, literasi keuangan menjadi topik hangat yang sedang gencar-gencarnya menjadi fokus dari pemerintah Indonesia. Literasi keuangan merupakan suatu pengetahuan yang mempengaruhi sikap pengambilan keputusan dan pengelolaan keuangan yang baik dan berkualitas untuk mencapai kesejahteraan (OJK, 2019). Sementara Lusardi (2014) menyatakan bahwa literasi keuangan adalah pengetahuan seorang individu untuk mengelola uang yang dimilikinya dengan tujuan mencapai kesejahteraan. Literasi keuangan sangat diperlukan oleh semua kalangan masyarakat untuk menunjang pengelolaan keuangan yang baik. Literasi keuangan juga sangat diperlukan untuk menjaga kelangsungan pertumbuhan ekonomi suatu negara. Meningkatnya literasi keuangan pada suatu negara akan menyebabkan peningkatan dalam penggunaan produk dan jasa keuangan.

Otoritas Jasa Keuangan pada tahun 2019 melaksanakan survei nasional yang menunjukan terjadi kenaikan indeks pada inklusi maupun literasi keuangan jika dibandingkan dengan tahun 2016. Indeks literasi keuangan pada tahun 2016 adalah sebesar 29,7 persen dan naik menjadi 38,03 persen ditahun 2019. Indeks inklusi keuangan dari tahun 2016 ke tahun 2019 juga mengalami kenaikan, yaitu dari 67,8 persen naik menjadi 76,19 persen. Kendati mengalami kenaikan, pencapaian literasi dan inkluasi keuangan Indonesia masih lebih rendah dibanding negara-negara ASEAN, terutama Singapura dan Malaysia.

Yushita (2017) menyatakan bahwa rendahnya pengetahuan mengenai literasi keuangan merupakan suatu masalah serius bagi masyarakat di Indonesia. Rendahnya pemahaman literasi keuangan yang dimiliki masyarakat dapat menyebabkan kerugian bagi masyarakat tersebut sendiri. Kerugian yang kemungkinan dialami oleh masyarakat diantaranya penurunan kondisi ekonomi, terciptanya inflasi, dan terciptanya lingkungan masyarakat yang semakin konsumtif. Memiliki pengetahuan literasi keuangan merupakan suatu keharusan agar bisa mendapat kehidupan yang sejahtera.

Pengelolaan keuangan secara umum masih dianggap tabu oleh masyarakat Indonesia (Wasita dkk., 2018). Perencanaan keuangan merupakan sebuah tanggung jawab yang harus dipersiapkan sedini mungkin oleh setiap individu (Navicas et al., 2013). Sangat dibutuhkan sebuah komitmen serta sinergitas dari semua pihak untuk menanamkan pemahaman terkait nilai-nilai literasi keuangan. Pemahaman ini bisa ditanamkan baik dari lingkungan keluarga maupun lingkungan sekolah (Rapih, 2016). Kekeliruan dalam melakukan perencanaan keuangan dapat menimbulkan kerugian di masa mendatang. Saat ini OJK tengah berupaya untuk meningkatkan inklusi dan literasi keuangan terutama dikalangan mahasiswa. Langkah ini merupakan suatu bentuk upaya meningkatkan peran mahasiswa terhadap perekonomian Indonesia. Setelah menyelesaikan pendidikannya pada perguruan tinggi, selanjutnya mahasiswa akan mulai bekerja dan memperoleh pengasilan. Dengan diperolehnya penghasilan maka mereka haruslah mampu secara mandiri untuk mengelola keuangannya. Maka dari itu sebagai generasi penerus, sudah seharusnya mahasiswa memiliki pengetahuan dan pemahaman tentang pengelolaa keuangan pribadi. Pemahaman tersebut akan sangat membantu mahasiswa untuk mengelola keuangannya dimasa mendatang.

Beberapa penelitian sebelumnya menyatakan bahwa pengetahuan mahasiswa terkait literasi keuangan berada dalam kategori rendah. Adapun peneliti yang mendapatkan hasil serupa diantaranya Krishna dkk (2010), Mendari \& Kewal (2013), Herawati (2017), Natalia dkk. (2019). Berbeda dengan hasil penelitian tersebut, penelitian yang dilakukan oleh Sakinah dan Mudakir (2018) menunjukan hasil bahwa pengetahuan mahasiswa pada hampir keseluruhan aspek literasi keuangan berada dalam kategori tinggi.

Kemampuan untuk mengelola keuangan yang baik bisa dilakukan ketika seorang individu memiliki pengetahuan yang baik terkait literasi keuangan. Margaretha \& Pambudhi (2015) serta Ningtyas (2019) menyatakan bahwa antara literasi keuangan dan perilaku keuangan memiliki hubungan yang positif. Hal serupa juga ditemukan dalam penelitian yang dilakukan oleh Busyro (2019). Dimilikinya pemahaman yang baik terkait literasi keuangan yang diterapkan dalam mengelola keuangan diharapkan dapat meningkatkan taraf hidup seseorang. Pemahaman Literasi keuangan 
seseorang sangat erat kaitannya dengan perilaku, kebiasaan, dan pengaruh- pengaruh lainnya yang berasal dari faktor eksternal. Sebuah faktor penting untuk memperoleh kesuksesan dapat dilihat dari kehandalan seseorang dalam mengelola keuangan, sehingga sangatlah penting bagi setiap individu untuk memiliki pemahaman yang baik terkait pengelolaan keuangan.

Mahasiswa semester 7 diploma empat jurusan Akuntansi Politeknik Negeri Bali sudah memperoleh matakuliah yang berkaitan dengan keuangan dan investasi, sehingga seharusnya sudah mempunyai pengetahuan yang baik akan literasi keuangan. Dengan pemahaman atas literasi keuangan tersebut, maka diharapkan mahasiswa mampu melakukan pengelolaan keuangan yang baik yang dicerminkan dari perilaku keuangan mahasiswa yang tidak konsumtif. Baiknya pengetahuan pengelolaan keuangan yang dimiliki mahasiswa akan dapat dilihat dari baiknya keputusan atas perilaku keuangan yang diambil. Contohnya adalah mahasiswa tersebut dapat menentukan saat terbaik untuk menginvestasikan uangnya pada produk jasa keuangan, dan lain sebagainya. Sangatlah penting bagi mereka untuk menerapkan pengetahuannya terkait literasi keuangan agar mampu mengatur keuangannya sehingga dapat hidup sejahtera dimasa depan. Berdasarkan uraian tersebut maka penelitian ini dilakukan untuk mengetahui pengaruh literasi keuangan pada perilaku keuangan mahasiswa.

\section{METODE PENELITIAN}

Studi ini dilakukan terhadap mahasiswa akuntansi Politeknik Negeri Bali. Teknik pengambilan sampel yang digunakan adalah purposive sampling dengan kriteria mahasiswa tersebut telah mendapatkan matakuliah terkait keuangan dan investasi. Berdasarkan teknik pengambilan sampel yang digunakan maka responden dalam penelitian ini terdiri dari 95 orang mahasiswa semester 7 Diploma Empat jurusan Akuntansi Politeknik Negeri Bali. Kuisioner digunakan untuk mengumpulkan data terkait literasi keuangan dan perilaku keuangan mahasiswa. Data dalam penelitian ini dianalisis menggunakan SPSS 22 untuk menggambarkan pengaruh literasi keuangan terhadap perilaku keuangan mahasiswa.

Teknik analisis dalam penelitian ini terdiri dari uji instrumen penelitian, uji normalitas dan uji regresi. Analisis validitas dan reabilitas digunakan untuk menguji instrumen penelitian. Uji validitas dan reabilitas berguna untuk mengetahui ke valid-an dan ke realiable-an dari setiap item yang terdapat dalam kuisioner. Pengujian instrumen penelitian dilakukan sebelum data sesungguhnya dikumpulkan. Instrumen dikatakan valid apabila korelasi $>0,30$, sedangkan instrument dikatakan reliabel apabila korelasi $>0,60$. Setelah dilakukan uji instrument, selanjutnya pengumpulan data dapat dilakukan. Sebelum data dapat dianalisa maka sebelumnya harus dilakukan uji normalitas. Data sampel harus memenuhi persyaratan distribusi normal (Hassan, 2005).

Pengujian normalitas dilakukan dengan metode One Sample Kormogrov Smirnov Test dengan tingkat signifikansi sebesar 5\%. Adapun kriteria dari pengujian ini adalah sebagai berikut, jika probabilitas asymp.sig (2- tailed) lebih besar dari 0,05 maka data berdistribusi normal, namun sebaliknya jika probabilitas asymp.sig (2- tailed) lebih kecil dari 0,05 maka data berdistribusi tidak normal.

Setelah uji normalitas terpenuhi, selanjutnya dilakukan analisis regresi linier sederhana untuk menganalisis data yang telah terkumpul terkait literasi keuangan dan perilaku keuangan mahasiswa. Adapun bentuk regresi dalam studi ini adalah sebagai berikut :

$$
\mathrm{Y}=\mathrm{a}+\mathrm{bX}
$$

Keterangan :

$\mathrm{Y}=$ Perilaku Keuangan Mahasiswa

$\mathrm{a}=$ Konstanta

$\mathrm{b}=$ Koefisien Regresi

$\mathrm{X}=$ Literasi Keuangan. 
Adapun hasil dari analisis regresi sederhana dapat dilihat dari nilai signifikansi. Signifikasi lebih kecil dari 0,05 menunjukan terdapat pengaruh antara literasi keuangan dengan perilaku keuangan. Namun jika signifikansinya lebih besar dari 0,05 maka tidak terdapat pengaruh antara literasi keuangan dengan perilaku keuangan mahasiswa.

\section{HASIL DAN PEMBAHASAN}

Untuk mengumpulkan data, peneliti menyebarkan dua puluh tujuh pertanyaan. Adapun dua puluh tujuh pertanyaan ini terdiri dari instrumen literasi keuangan sebanyak tujuh belas pertanyaan dan perilaku keuangan mahasiswa sebanyak sepuluh pertanyaan. Sebelum data dapat dikumpulkan, maka harus dilakukan uji instrumen terlebih dahulu untuk memastikan instrumen yang digunakan bersifat valid dan reliabel. Berikut merupakan hasil pengujian validitas dan reabilitas instrumen literasi keuangan (X) dan perilaku keuangan mahasiswa (Y).

Tabel 1.

Hasil uji validitas instrumen literasi keuangan.

\begin{tabular}{ccc}
\hline LITERASI KEUANGAN & Pearson Correlation & Keterangan \\
\hline P 1 & $0.700^{* *}$ & valid \\
P 2 & $0.552^{* *}$ & valid \\
P 3 & $0.454^{*}$ & valid \\
P 4 & $0.441^{*}$ & valid \\
P 5 & $0.725^{* *}$ & valid \\
P 6 & $0.362^{*}$ & valid \\
P 7 & $0.503^{* *}$ & valid \\
P 8 & $0.491^{* *}$ & valid \\
P 9 & $0.694^{* *}$ & valid \\
P 10 & $0.565^{* *}$ & valid \\
P 1 & $0.583^{* *}$ & valid \\
P 12 & $0.715^{* *}$ & valid \\
P 13 & $0.659^{* *}$ & valid \\
P 14 & $0.700^{* *}$ & valid \\
P 15 & $0.680^{* *}$ & valid \\
P 16 & $0.633^{* *}$ & valid \\
P 17 & $0.727^{* *}$ & valid \\
\hline
\end{tabular}

Sumber : data diolah, 2020

Tabel 2.

Hasil Uji Reabilitas Instrument Literasi Keuangan

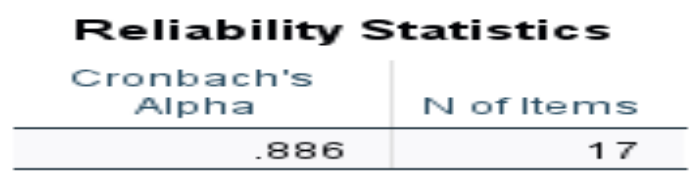

Sumber : data diolah, 2020

Hasil uji validitas instrument literasi keuangan seperti yang terlihat pada tabel 1, menunjukan bahwa seluruh pertanyaan literasi keuangan adalah valid. Hal ini dapat dilihat bahwa seluruh item pertanyaan literasi keuangan memiliki nilai pearson correlation lebih besar dari 0,30. 
Hasil uji reabilitas instrument literasi keuangan seperti yang terlihat pada tabel 2 menunjukan instrument literasi keuangan adalah reliabel. Hal ini dapat dilihat dari nilai cronbach's Alpha sebesar 0,886 lebih besar dari 0,60.

Tabel 3.

Hasil Uji Validitas Instrumen Perilaku Keuangan Mahasiswa

\begin{tabular}{ccc}
\hline PERILAKU KEUANGAN & & Keterangan \\
MAHASISWA & Pearson Correlation & \\
\hline P 1 & $0.378^{* *}$ & valid \\
P 2 & $0.552^{* *}$ & valid \\
P 3 & $0.694^{*}$ & valid \\
P 4 & $0.615^{* *}$ & valid \\
P 5 & $0.541^{* *}$ & valid \\
P 6 & $0.715^{* *}$ & valid \\
P 7 & $0.542^{* *}$ & valid \\
P 8 & $0.758^{* *}$ & valid \\
P 9 & $0.583^{* *}$ & valid \\
P 10 & $0.564^{* *}$ & valid \\
\hline
\end{tabular}

Sumber: data diolah, 2020

Hasil uji validitas instrument perilaku keuangan mahasiswa seperti yang terlihat pada tabel 3 menunjukan bahwa seluruh item pertanyaan terkait perilaku keuangan mahasiswa memiliki nilai pearson correlation di atas 0,30 . Sehingga seluruh instrument perilaku keuangan mahasiswa valid.

Tabel 4.

Hasil Uji Reabilitas Instrumen Perilaku Keuangan Mahasiswa

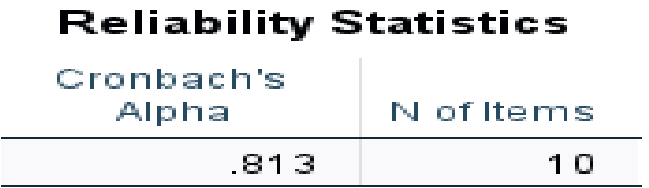

Sumber: data diolah, 2020

Hasil uji reabilitas seperti yang terlihat pada tabel 4, menunjukan bahwa cronbach's Alpha instrumen perilaku keuangan mahasiswa memiliki nilai sebesar 0,813 lebih besar dari 0,60. Nilai ini menunjukan bahwa instrumen perilaku keuangan adalah reliabel. Setelah uji instrumen penelitian dilakukan, selanjutnya kuisioner dapat disebarkan untuk memperoleh data terkait literasi keuangan dan perilaku keuangan mahasiswa. Setelah data terkumpul selanjutnya dilakukan pengujian normalitas. 
Tabel 5.

Hasil Uji Normalitas

\begin{tabular}{|c|c|c|c|}
\hline \multicolumn{4}{|c|}{ One-Sample Kolmogorov-Smirnov Test } \\
\hline & & & $\begin{array}{l}\text { Unstandardiz } \\
\text { ed Residual }\end{array}$ \\
\hline \multicolumn{3}{|l|}{$\mathrm{N}$} & 95 \\
\hline \multirow[t]{2}{*}{ Normal Parameters ${ }^{a \cdot b}$} & \multicolumn{2}{|l|}{ Mean } & .0000000 \\
\hline & \multicolumn{2}{|l|}{ Std. Deviation } & 3.68557341 \\
\hline \multirow{3}{*}{ Most Extreme Differences } & \multicolumn{2}{|l|}{ Absolute } & .079 \\
\hline & \multicolumn{2}{|l|}{ Positive } & .066 \\
\hline & \multicolumn{2}{|l|}{ Negative } & -.079 \\
\hline \multicolumn{3}{|l|}{ Test Statistic } & .079 \\
\hline \multicolumn{3}{|l|}{ Asymp. Sig. (2-tailed) ${ }^{c}$} & .170 \\
\hline \multirow{3}{*}{$\begin{array}{l}\text { Monte Carlo Sig. (2- } \\
\text { tailed) }\end{array}$} & \multicolumn{2}{|l|}{ Sig. } & .150 \\
\hline & \multirow[t]{2}{*}{9996 Confidence Interval } & Lower Bound & .141 \\
\hline & & Upper Bound & .159 \\
\hline \multicolumn{4}{|c|}{ a. Test distribution is Normal. } \\
\hline \multicolumn{4}{|l|}{ b. Calculated from data. } \\
\hline \multicolumn{4}{|c|}{ c. Lilliefors Significance Correction. } \\
\hline \multicolumn{4}{|c|}{$\begin{array}{l}\text { d. Lilliefors' method based on } 10000 \text { Monte Carlo samples with starting seed } \\
334431365 \text {. }\end{array}$} \\
\hline
\end{tabular}

Hasil uji normalitas seperti yang terlihat pada tabel 5 dapat menunjukan bahwa nilai asymp. Sig. (2-tailed) adalah sebesar 0,170 lebih besar dari 0,05. Hal tersebut menunjukan bahwa data dalam penelitian berdistribusi normal. Setelah uji normalitas telah terpenuhi maka selanjutnya dapat dilakukan analisis regresi linier sederhana untuk menguji pengaruh literasi keuangan pada perilaku keuangan mahasiswa.

Tabel 6.

\section{Hasil Uji Regresi}

\begin{tabular}{|c|c|c|c|c|c|c|}
\hline \multicolumn{7}{|c|}{ ANOVA $^{a}$} \\
\hline Model & & $\begin{array}{l}\text { Sum of } \\
\text { Squares }\end{array}$ & $\mathrm{df}$ & Mean Square & $\mathrm{F}$ & Sig. \\
\hline \multirow[t]{3}{*}{1} & Regression & 253.513 & 1 & 253.513 & 18.465 & $.000^{\mathrm{b}}$ \\
\hline & Residual & 1276.844 & 93 & 13.730 & & \\
\hline & Total & 1530.358 & 94 & & & \\
\hline
\end{tabular}

a. Dependent Variable: Perilaku Keuangan Mahasiswa

b. Predictors: (Constant), Literasi Keuangan

Sumber : data diolah, 2020

Tabel 7.

Hasil Model Summary

\begin{tabular}{|c|c|c|c|c|}
\hline \multicolumn{5}{|c|}{ Model Summary } \\
\hline Model & $\mathrm{R}$ & R Square & $\begin{array}{c}\text { Adjusted R } \\
\text { Square }\end{array}$ & $\begin{array}{l}\text { Std. Error of } \\
\text { the Estimate }\end{array}$ \\
\hline 1 & $.407^{a}$ & .166 & .157 & 3.70534 \\
\hline
\end{tabular}


Hasil pengujian regresi yang dapat dilihat pada tabel 6, menunjukan bahwa nilai $\mathrm{F}$ hitung adalah 18,465 dengan nilai sig 0,000 lebih kecil dari 0,05. Hasil ini menunjukan bahwa model regresi dalam penelitian ini dapat memprediksi variabel partisipasi, atau dapat diartikan terdapat pengaruh antara variabel literasi keuangan $(\mathrm{X})$ pada perilaku keuangan mahasiswa $(\mathrm{Y})$.

Untuk mendukung hasil tersebut, berdasarkan tabel 7, dapat diketahui bahwa R Square bernilai 0,166 . Hal ini menunjukan bahwa pengaruh variabel literasi keuangan terhadap perilaku keuangan mahasiswa adalah sebesar $16,6 \%$ dan sisanya dipengaruhi oleh variabel lain yang tidak termasuk kedalam model.

\section{SIMPULAN DAN SARAN}

Dari pengujian yang telah dilakukan, dapat ditarik kesimpulan bahwa literasi keuangan berpengaruh terhadap perilaku keuangan mahasiswa. Hasil ini sesuai dengan teori literasi keuangan yang menyatakan bahwa keputusan keuangan seorang individu akan sangat dipengaruhi oleh pengetahuan keuangan yang dimiliki. Mahasiswa jurusan akuntansi Politeknik Negeri Bali telah memiliki pemahaman yang baik terkait dengan literasi keuangan. Pemahaman terkait literasi keuangan ini sudah diterapkan sehingga mahasiswa mampu menerapkan perilaku keuangan yang baik. Hal ini tentu sangat berguna, karena mahasiswa yang merupakan generasi penerus sudah mulai belajar melakukan pengelolaan keuangan yang baik.

Adapun saran dalam penelitian ini adalah edukasi terkait literasi keuangan harus selalu diberikan kepada mahasiswa agar pemahaman mahasiswa terkait literasi keuangan dapat terus ditingkatkan. Ketika pemahaman literasi keuangan meningkat maka pengelolaan keuangan yang tercermin dari perilaku keuangan juga akan meningkat. Sehingga sasaran OJK untuk meningkatkan peran mahasiswa terhadap perekonomian Indonesia dapat tercapai. Penelitian ini hanya dilakukan terhadap mahasiswa jurusan akuntansi, dimana mahasiswa tersebut telah memperoleh pengetahuan terkait keuangan dan investasi. Penelitian selanjutnya disarankan untuk meneliti mahasiswa yang berasal dari luar jurusan akuntansi. Mahasiswa diluar jurusan akuntansi, tidak mendapatkan pengetahuan terkait keuangan dan investasi. Sehingga nantinya dapat dilihat apakah terdapat perbedaan perilaku keuangan antara mahasiswa yang telah memperoleh pengetahuan terkait literasi keuangan dengan mahasiswa yang tidak memperoleh literasi keuangan.

\section{REFERENSI}

Busyro, Wahyi. (2019). Pengaruh Literasi Keuangan Terhadap Perilaku Pengelolaan Keuangan Mahasiswa (Studi Kasus Pada Mahasiswa Fakultas Ekonomi Dan Bisnis Universitas Muhammadiyah Riau). Jurnal ISLAMIKA, 2(1), 34-37

Cummins M., Haskel J. H., \& Jenkins S.(2009). Financial Attitude And Spanding Habits Of University Fresmen. Journal Of Economic Education Research, 10(1), 3-16

Hassan, Suryono. (2005). Statistik Pedoman, Teori dan Aplikasi. Surakarta : LPP dan UNS Press.

Herawati, Nyoman Trisna. (2017). Tingkat Literasi Keuangan Mahasiswa Serta Faktor-Faktor yang Mempengaruhinya. Seminar Nasional Riset Inovatif, 131-137.

Krishna, Ayu., Rofaida, Rofi.,\& Sari, Maya. (2010). Analisis Tingkat Literasi Keuangan Di Kalangan Mahasiswa dan Faktor-Faktor Yang Mempengaruhinya. ( Survey Pada Mahasiswa Universitas Pendidikan Indonesia. Proceedings of The 4th International Conference on Teacher Education, 4(1) 552-560.

Lusardi, A dan O.S. Mitchell. (2014). The Economic Importance of Financial Literacy: Theory and Evidence. Journal of Economic Literature, 52(1), 5-44

Margaretha, Farah dan Pambudhi, RA. (2015). Tingkat Literasi Keuangan pada mahasiswa S1 Fakultas Ekonomi. Jurnal Manajemen dan Kewirausahaan, 17(1), 76-85.

Mendari, Anastasia Sri dan Kewal, Suramaya Suci. (2013). Tingkat Literasi Keuangan Di Kalangan Mahasiswa STIE MUSI. Jurnal Economica, 9(2), 130-140Natalia, DE., Murni, Sri., dan Untu, VN. (2019). Analisis 
Tingkat Literasi Dan Pengelolaan Keuangan Pribadi Mahasiswa Di Fakultas Ekonomi Dan Bisnis Univeristas Sam Ratulangi. Jurnal EMBA, 7(2), 2131-2140.

Navickas, M ,Tadas G dan Emilia K, (2013).Influence on Financial Literacy on Management of Personal Finances in A Young Households, Lithuania .

Ningtyas, Mega Noerman. (2019). Literasi Keuangan Pada Generasi Milenial. Jurnal Ilmiah Bisnis dan Ekonomi Asia, 13(1), 20-27

Otoritas Jasa Keuangan. (2019). Siaran Pers OJK 2019 Indeks Literasi dan Inklusi Keuangan Meningkat. https://www.ojk.go.id/id/berita-dan-kegiatan/siaran-pers/Pages/Siaran-Pers-Survei-OJK-2019-IndeksLiterasi-Dan-Inklusi-Keuangan-Meningkat.aspx

Rapih, Subroto. (2016). Pendidikan Literasi Keuangan Pada Anak:Mengapa Dan Bagaimana?. Scholaria, 6(2), 14-28

Sakinah, Gina dan Mudakir, Bagio. (2018) Analisis Literasi Keuangan Mahasiswa S-1 Fakultas Ekonomika Dan Bisnis Universitas Diponegoro Angkatan 2014-2017. Jurnal Dinamika Ekonomi Pembangunan, 1(2)

Yushita, Amanita Novi. (2017). Pentingnya Literasi Keuangan Bagi Pengelolaan Keuangan Pribadi. Jurnal Nominal , 6(1), 11-26.

Wasita, PAA., Pradnyani, NLPSP., Cahyadi, LDCR., Artaningrum, RG., Lasmini, NN (2018). Pengeloaan Keuangan Di Era Milineal Bagi Siswa Siswi Di SMA Kristen Harapan. Seminar Nasional Aplikasi Iptek, 2(1), 197-202 